\title{
The evaluation of sleep quality, anxiety disorder and depression in older adults with Parkinson disease
}

\author{
๑Gülay İlkhan Daşdemir ${ }^{1}$, ĐHakan Çelikhisar², \Aslı Kılavuz ${ }^{3}$ \\ ${ }^{1}$ Tire Public Hospital, Department of Chest Diseases, Tire, İzmir, Turkey \\ ${ }^{2}$ İzmir Metropolitan Municipality Hospital, Department of Chest Diseases, Yenisehir, İzmir, Turkey \\ ${ }^{3}$ Ege University Faculty of Medicine, Department of Internal Medicine, Division of Geriatrics, Bornova, İzmir, Turkey
}

Cite this article as: Daşdemir Gİ, Çelikhisar $\mathrm{H}$, Kılavuz A. The evaluation of sleep quality, anxiety disorder and depression in older adults with Parkinson disease. J Health Sci Med 2021; 4(2): 147-153.

\begin{abstract}
Aim: The aim of this study was to examine the prevalence ratios of sleep disorder, anxiety and depression in older adults with Parkinson disease in addition to the relationship between these complaints and the stage and duration of the disease.

Material and Method: Epworth sleepiness scale, Pittsburgh sleep quality index, Insomnia severity index, Beck depression inventory, Hamilton anxiety scale were applied on a total of 585 older adults followed up with Parkinson disease diagnosis. The acquired results were interpreted by comparing with the data of the control group comprised of 585 healthy individuals.

Results: A total of 585 older adult with Parkinson disease and 585 healthy controls were included in the study. Each group was comprised of 255 female (43.59\%) and 330 male (56.41\%) participants. Mean age of the Parkinson group was $68.14 \pm 7.01$ years, whereas mean age of the control group was $65.08 \pm 6.43$ years. Mean Hoehn Yahr scale was determined in the Parkinson group as 1.8; while mean UPDRS was 29.8. Daytime functions and subjective sleep quality were worse at a statistically significant level in the patient group according to Pittsburgh sleep quality index ( $\mathrm{p}=0.014, \mathrm{p}=0.019$, respectively). The most significant difference was observed in ESS when the scale scores of the patient and control groups were compared $(\mathrm{p}<0.001)$. A positive and statistically significant correlation was determined between the Beck depression inventory score and unified Parkinson's disease rating scale and Hoehn Yahr scale ( $\mathrm{p}=0.023, \mathrm{p}=0.034$, respectively). While depression ratio increases with increasing stages of the disease, anxiety ratios increased with increasing disease duration. A positive and statistically significant correlation was determined between the weight of the disease and the score obtained from the somatic section of HAM-A $(\mathrm{p}=0.022)$.

Conclusion: The presence of depression and anxiety should be questioned especially in older adult with Parkinson disease who are clinically more severe and who have been undergoing treatment for a longer period of time; patients with treatment related complications should be evaluated with regard to sleep disorders. It should be kept in mind that the Parkinson disease is not related only with motor symptoms but that an effective treatment of the non-motor symptoms will also improve the quality of life of the patients.
\end{abstract}

Keywords: Anxiety, depression, older adults, Parkinson disease, sleep disorders

\section{INTRODUCTION}

Sleep disturbances associated with Parkinson disease are common and have many negative effects on the quality of life of patients with Parkinson disease (1). Daytime sleepiness, insomnia, REM-sleep behaviour disorder, and restless-legs syndrome are the most of observed sleep disorders in people with Parkinson disease (2). In order to identify sleep disturbances, regular screening using validated questionnaires such as the Pittsburgh sleep quality index (PSQI) or the medical outcomes study sleep scale are recommended (3). In order to assess daytime sleepiness, the usage of Epworth sleepiness scale (ESS) (4), the inappropriate sleep composite score or the Stanford sleepiness scale are recommended (5).

Parkinson disease which is the second most frequently observed neurodegenerative disease in the world affects $1 \%$ of individuals above the age of 60 (6). Whereas it has a prevalence ratio of $111 / 100.000$ in our country (7). Known as a movement disorder and characterized primarily by motor symptoms such as tremor, rigidity, bradykinesia; the non-motor symptoms of the disease which significantly reduce the quality of life of patients such as depression, anxiety disorder, daytime sleepiness and insomnia are generally ignored (8). 
As is the case in all other chronic diseases, various psychiatric problems can also be observed in Parkinson disease. Depression is the most frequently observed psychiatric problem in patients with Parkinson disease with a prevalence ranging between $17-50 \%(9,10)$. Anxiety disorders can be seen in patients with Parkinson disease at ratios of $40-82 \%$ which is higher when compared with the normal population or other chronic neurological diseases (11-15). It has been reported in previous studies that the number of depression and anxiety cases increase with increasing stage and duration of the disease (16). Various problems such as insomnia, daytime sleepiness can be observed in patients with Parkinson disease. The prevalence of insomnia is around $60-76 \%$ in patients with Parkinson disease $(17,18)$. The correlation between depression and sleep disorder in patients with Parkinson disease has been put forth in previous studies (19). Sleep disorders can be observed due to the disease itself as well as the medications used. Daytime sleepiness is observed most frequently in this patient group from among all sleep disorders. It may be followed by insomnia, sleep quality disorder at varying ratios $(17,18,20)$.

This study specifically focused on older adult with Parkinson disease. In the study, the ratios of depression, anxiety and sleep disorders in older patients with Parkinson disease were examined along with the relationship between these complaints and the stage and duration of the disease. So our study tries to put forth the necessity for clinicians to question these generally overlooked symptoms in older adult with Parkinson disease.

\section{MATERIAL AND METHOD}

\section{Study Design and Participants}

The study was performed by the local ethical committee of Bezmialem Vakif University, including the number of the approval document and the date of the approval (Registration number: 2011- KAEK-25 2019/01-03). All procedures were performed adhered to the ethical rules and the Helsinki Declaration of Principles.

We recruited 585 adults aged 65 and over with Parkinson disease consecutively from the Department of Neurology, Training and Research Hospital in İstanbul, Metropolitan Municipality Hospital in Izmir, from September 2019 to January 2020. The control group was comprised of patient relatives and healthy hospital staff members without any neurological and systemic disease.

The patients diagnosed with Parkinson disease by a neurology specialist according to the United Kingdom Brain Bank Parkinson Disease Diagnostic Criteria were included in the study (21). Staging of the disease was carried out via Hoehn Yahr scale (HYS), whereas the clinical weight assessment was performed via unified Parkinson's disease rating scale (UPDRS). Unified Parkinson's disease rating scale is comprised of four main sections evaluating the mental states, behaviors and psychological moods of the patients along with their daily life activities, motor functions and treatment complications. The 42 items of the test were scored between $0-4$. High scores indicated bad clinical development (22). There is a Turkish inter-rater reliability study of UPDRS (23).

Hoehn-Yahr scale was used for evaluating the severity and progression of the disease (24). Brain tomography or cranial magnetic resonances were examined for all patients. Factors such as medications, poisonings, vascular reasons, hypoxia, trauma, infections, normal pressure hydrocephaly and brain tumors which may lead to secondary Parkinsonism along with Parkinson plus syndromes were excluded from the study. All participants were subject to detailed physical and neurological examination after which their histories and demographic characteristics were recorded.

Beck depression inventory developed by Beck et al. (25) was used for evaluating depression. The purpose of this test is to measure the level of depressive symptoms and higher total scores indicate the severity of the level of depression. The inventory is comprised of 21 self-report questions with a maximum score of 63 . In the present study, scores of 0-9 represented $=$ minimal depression, 10-16=mild depression, 17-29=moderate depression, $30-63=$ severe depression (25). It was shown by Hisli to be valid and reliable in a Turkish sample (26).

The Hamilton anxiety scale (HAM-A) developed by Hamilton is comprised of two sections that question the physical and mental effects of anxiety. Including a total of 14 questions, the test has a maximum score of 56 with scores ranging between 6-14 indicating minor anxiety; whereas scores of 15 and above indicated major anxiety. Those with scores of 6 and above from the HAM-A scale were evaluated as having anxiety (27). The Turkish validity and reliability study of HAM was conducted by Yazic1 et al. (28).

Three different tests were used for evaluating the sleep quality in patients with Parkinson disease. These were ESS, PSQI and Insomnia severity index (ISI).

Epworth sleepiness scale developed by Johns MJ (4) in 1991 was used for evaluating daytime sleepiness. The maximum score that can be obtained from this test is 24 with scores of and above indicating issues of daytime sleepiness (4). The Turkish validity and reliability study of ESS was conducted by İzci et al. (29). 
The Pittsburgh sleep quality index developed by Buysse et al. (3) is a test that evaluates sleep quality and disorder during the past one month. The scale is comprised of seven sub-titles of Subjective sleep quality (K1), sleep latency (K2), sleep duration (K3), sleep efficiency (K4), sleep disturbances (K5), use of sleeping medication (K6) and daytime dysfunction (K7) with a maximum score of 21. Total PUKİ scores of above 5 indicate bad sleep quality (3). The Turkish validity and reliability of the Pittsburgh Sleep Quality Index was conducted by Ağargün et al. (30)

Insomnia severity index was developed in 2001 by Bastien et al. (31) for evaluating insomnia severity. Comprised of a total of 7 questions, the maximum score that can be obtained from the test is 28 . Scores of $0-7$ indicate clinically insignificant insomnia, scores of 8-14 indicate insomnia lower threshold, scores of 15-21 indicate clinical insomnia (moderate level) whereas scores of 2228 indicate clinical insomnia (severe) (31). The Turkish validity and reliability of the Pittsburgh Sleep Quality Index was conducted by Boysan et. al. (32).

\section{Statistical Analysis}

Statistical analyses were performed using SPSS version 21.0 (SPSS Inc. Chicago, IL, USA). Shapiro-Wilk test was used for evaluating whether the variables comply with the normal distribution or not. The variables that comply with the normal distribution were presented as mean \pm standard deviation with the t-test used for comparisons between two independent groups. The variables that do not comply with the normal distribution were presented as median (minimum-maximum) values with the Mann-Whitney U test used for the comparisons between two independent groups. Categorical variables were presented with frequency and percentage values [n (\%)] with the Pearson chi-square test, Fisher's exact chi-square test and Fisher-Freeman-Halton tests used for comparisons. Spearman correlation coefficient was used for examining the relationships between the variables. The level of significance was taken as $\mathrm{p}<0.05$.

\section{RESULTS}

A total of 585 older adult with Parkinson disease and 585 healthy controls were included in the study. Each group was comprised of 255 female and 330 male participants. Mean age of the Parkinson group was $68.14 \pm 7.01$ years, whereas mean age of the control group was $65.08 \pm 6.43$ years. Mean HYS was determined in the Parkinson group as 1.8; while mean UPDRS was 29.8. There were no statistically significant differences between the two groups with regard to age, gender, BMI, hypertension, diabetes and restless leg syndrome (RLS) prevalence. Table 1 presents the demographic characteristics of the patient and control groups.

\begin{tabular}{|c|c|c|c|}
\hline Variables & Patient, $(\mathrm{n}, \%)$ & Control (n,\%) & $\mathbf{p}$ \\
\hline Gender & & & 1.000 \\
\hline Male & $330(56.41)$ & $330(56.41)$ & - \\
\hline Female & 255 (43.59) & $255(43.59)$ & - \\
\hline Age $^{\star}$ & $68.14 \pm 7.01$ & $65.08 \pm 6.43$ & 0.079 \\
\hline $\mathrm{BMI}^{*}$ & $29.01 \pm 5.41$ & $27.31 \pm 3.11$ & 0.161 \\
\hline Marital status & & & 0.621 \\
\hline Married & $30(5.13)$ & $15(2.56)$ & - \\
\hline Single & $465(79.49)$ & $435(74.36)$ & - \\
\hline Widow & $90(15.38)$ & $135(23.08)$ & - \\
\hline Hypertension & $255(43.59)$ & $210(35.89)$ & 0.711 \\
\hline Diabetes mellitus & $180(30.77)$ & $60(10.25)$ & 0.389 \\
\hline Restless leg syndrome & $120(20.51)$ & $105(17.95)$ & 1.087 \\
\hline
\end{tabular}

Daytime sleepiness was observed to be high at a statistically significant level in the Parkinson group according to ESS $(\mathrm{p}<0.001)$. While the daytime sleepiness was $53.85 \%$ in the Parkinson group; this ratio was determined as $5.12 \%$ in the control group. The ratio of those with bad sleep quality according to PSQI was $82.06 \%$ in the Parkinson group, whereas the ratio was $61.54 \%$ in the control group; however, the difference was not statistically significant $(\mathrm{p}=0.219)$. A statistically significant difference could not be determined between the two groups when BDI, HAM-A, ISI and PUKI were compared. Table 2 presents the correlations for the patient and control groups.

\begin{tabular}{|c|c|c|c|}
\hline Variables & Patient (n,\%) & Control (n,\%) & $\mathbf{p}$ \\
\hline HAM-A & & & 0.211 \\
\hline None & $315(53.85)$ & $195(33.33)$ & \\
\hline Minor & $240(41.03)$ & $270(46.15)$ & \\
\hline Major & $30(5.12)$ & $120(20.52)$ & \\
\hline BDI & & & 0.692 \\
\hline Minimal & $435(74.36)$ & $360(61.53)$ & \\
\hline Mild & $105(17.95)$ & $165(28.21)$ & \\
\hline Moderate & $45(7.69)$ & $60(10.26)$ & \\
\hline ISI & & & 0.889 \\
\hline Insignificant & $510(87.17)$ & $525(89.74)$ & \\
\hline Lower threshold & $30(5.13)$ & $45(3.33)$ & \\
\hline Moderate & $30(5.13)$ & $15(2.56)$ & \\
\hline Severe & $15(2.57)$ & $0(0.00)$ & \\
\hline ESS & & & $<0.001$ \\
\hline Negative & $270(46.15)$ & $555(94.88)$ & \\
\hline Positive & $315(53.85)$ & $30(5.12)$ & \\
\hline PSQI & & & 0.219 \\
\hline Good & $105(17.94)$ & $225(38.46)$ & \\
\hline Poor & $480(82.06)$ & $360(61.54)$ & \\
\hline
\end{tabular}


The most significant difference was observed in ESS when the scale scores of the patient and control groups were compared. While the mean ESS score for the patient group was 9; the mean score was 3 for the control group $(\mathrm{p}<0.001)$. The scores obtained from the 1st component of PSQI that reflects subjective sleep quality and the 7 th component that reflects the daytime functions were higher at a statistically significant level in the Parkinson group compared to the control group ( $\mathrm{p}=0.014, \mathrm{p}=0.019$, respectively). Interestingly, ISI score was higher in the control group $(p=0.045)$. There were no statistically significant differences between the two groups with regard to the other variables. Table 3 presents the comparison of the test scores for the patient and control groups.

A positive and statistically significant correlation was determined between the BDI score and UPDRS and HYS. A positive and statistically significant correlation was determined between the weight of the disease and the score obtained from the somatic section of HAM-A. This is an indication that the prevalence of anxiety increased with increasing duration of the disease. A positive and statistically significant correlation was determined between the 4th section of UPDRS including treatment complications and the 5th component of HAM-A and PSQI that includes sleep disorders. The prevalence of anxiety and sleep disorders increased with increasing complications of the disease. A negative and statistically significant correlation was determined between the 3rd component of PSQI defining sleep duration and the 1st section of UPDRS that reflects the mental state, behavior and mental state. Table 4 presents the correlations in the patient group.
Table 3. Testing between patient and control groups comparison of scores

\begin{tabular}{|c|c|c|c|}
\hline Variables & Patient (n) & Control (n) & $\mathbf{p}$ \\
\hline $\begin{array}{l}\text { Beck depression } \\
\text { inventory (BDI) }\end{array}$ & 90 & 120 & 0.633 \\
\hline $\begin{array}{l}\text { Hamilton anxiety scale- } \\
\text { psychic HAM-A(P) }\end{array}$ & 30 & 15 & 0.201 \\
\hline $\begin{array}{l}\text { Hamilton anxiety scale- } \\
\text { somatic HAM-A(S) }\end{array}$ & 45 & 65 & 0.614 \\
\hline $\begin{array}{l}\text { Hamilton anxiety scale } \\
\text { (HAM-A) }\end{array}$ & 75 & 105 & 0.236 \\
\hline $\begin{array}{l}\text { Insomnia Severity Index } \\
\text { (ISI) }\end{array}$ & 15 & 60 & 0.045 \\
\hline $\begin{array}{l}\text { Epworth sleepiness scale } \\
\text { (ESS) }\end{array}$ & 135 & 45 & $<0.001$ \\
\hline $\begin{array}{l}\text { Pittsburg sleep quality } \\
\text { index (PSQI) K1 }\end{array}$ & 15 & 0 & 0.013 \\
\hline $\begin{array}{l}\text { Pittsburg sleep quality } \\
\text { index (PSQI) K2 }\end{array}$ & 15 & 15 & 0.558 \\
\hline $\begin{array}{l}\text { Pittsburg sleep quality } \\
\text { index (PSQI) K3 }\end{array}$ & 35 & 15 & 0.075 \\
\hline $\begin{array}{l}\text { Pittsburg sleep quality } \\
\text { index (PSQI) K4 }\end{array}$ & 0 & 0 & 0.153 \\
\hline $\begin{array}{l}\text { Pittsburg sleep quality } \\
\text { index (PSQI) K5 }\end{array}$ & 15 & 15 & 0.880 \\
\hline $\begin{array}{l}\text { Pittsburg sleep quality } \\
\text { index (PSQI) K6 }\end{array}$ & 0 & 15 & 0.374 \\
\hline $\begin{array}{l}\text { Pittsburg sleep quality } \\
\text { index (PSQI) K7 }\end{array}$ & 15 & 0 & 0.020 \\
\hline $\begin{array}{l}\text { Pittsburg sleep quality } \\
\text { index Total }\end{array}$ & 105 & 105 & 0.343 \\
\hline
\end{tabular}

\begin{tabular}{llllccccc}
\multicolumn{2}{l}{ Table 4. Correlation in the patient group } & & & & & & & \\
Variables & HYS & Initial & UPDRS1 & UPDRS2 & UPDRS3 & UPDRS4 & UPDRS-T & p \\
\hline BDI & 0.004 & 0.720 & 0.470 & 0.181 & 0.599 & 0.209 & 0.051 & 0.120 \\
HAM-A (P) & 0.035 & 0.359 & 0.911 & 0.259 & 0.839 & 0.129 & 0.519 & 0.481 \\
HAM-A (S) & 0.669 & 0.709 & 0.512 & 0.851 & 0.461 & 0.141 & 0.931 & 0.010 \\
HAM-A (T) & 0.107 & 0.581 & 0.321 & 0.391 & 0.810 & 0.007 & 0.710 & 0.121 \\
ISI & 0.510 & 0.371 & 0.931 & 0.549 & 0.869 & 0.389 & 0.571 & 0.959 \\
ESS & 0.418 & 0.089 & 0.279 & 0.841 & 0.949 & 0.391 & 0.841 & 0.609 \\
PSQI K1 & 0.311 & 0.669 & 0.701 & 0.829 & 0.351 & 0.869 & 0.349 & 0.949 \\
PSQI K2 & 0.719 & 0.389 & 0.359 & 0.709 & 0.951 & 0.709 & 0.851 & 0.689 \\
PSQI K3 & 0.279 & 0.349 & 0.029 & 0.741 & 0.571 & 0.249 & 0.899 & 0.851 \\
PSQI K4 & 0.467 & 0.329 & 0.468 & 0.679 & 0.749 & 0.281 & 0.443 & 0.877 \\
PSQI K5 & 0.426 & 0.439 & 0.581 & 0.062 & 0.281 & 0.039 & 0.339 & 0.069 \\
PSQI K6 & 0.249 & 0.610 & 0.359 & 0.179 & 0.571 & 0.321 & 0.211 & 0.161 \\
PSQI K7 & 0.631 & 0.589 & 0.131 & 0.331 & 0.161 & 0.731 & 0.599 & 0.861 \\
PSQI Total & 0.919 & 0.331 & 0.219 & 0.191 & 0.531 & 0.589 & 0.459 & 0.259 \\
\hline
\end{tabular}

BDI, Beck depression inventory; HYS, Hoehn Yahr scale; UPDRS, Unified Parkinson's disease rating scale; HAM-A, Hamilton anxiety scale; (P), psychic; (S), Somatic; (T), Total; ISI, Insomnia severity index; ESS, Epworth sleepiness scale; PSQI, Subjective sleep quality; K1, Subjective sleep quality; K2, Sleep latency; K3, Sleep duration; K4, Sleep efficiency; K5, Sleep disturbances; K6, Use of sleeping medication; K7, Daytime dysfunction 


\section{DISCUSSION}

In our study, minimal depressive symptoms were observed in $7 \%$ of the patients with Parkinson disease, mild depression in $17 \%$ and moderate depression in $3 \%$. Severe depression was not observed in any of our patients. A positive correlation was determined in our study between the BDI score and UPDRS and HYS. These findings supported the opinion that the prevalence of depression increases with increasing severity of the diseases and were in accordance with literature. In this study, daytime sleepiness was higher at a statistically significant level in the Parkinson group. Another interesting result of our study is; while depression ratio increases with increasing stages of the disease, anxiety ratios increased with increasing disease duration.

When we make an evaluation with the results of similar studies in the literature; it was determined as a result of a study carried out on patients with Parkinson disease with 80 participants that the ratios are $41.25 \%, 32.5 \%$ and $87 \%$ for depression, anxiety and the coupling of depression and anxiety, respectively. The number of depression and anxiety cases increased with increasing of UPDRS severity score $(16,17)$.

It was determined in another study that the ratio of anxiety was higher at a statistically significant level among patients with Parkinson disease compared to the control group (17). The number of anxiety cases increased with increasing severity and duration of the disease. The anxiety ratio in our study in the Parkinson group was determined as $45.73 \%$, however no statistically significant difference could be determined with the control group. High anxiety ratio in the control group may be due to the fact that majority of the control group is comprised of healthcare employees. While a statistically significant relationship could not be determined in our study between the severity of the disease and anxiety; a statistically significant relationship was determined between the somatic part of HAM-A and disease duration. This is an indication that the somatic complaints of the patients increased with increasing disease duration. anxiety prevalence also increased in our study with the increasing of treatment complications. This can be evaluated as a non-motor symptom that develops during the course of the disease while it should also be kept in mind that it can be related with a side effect of the medications used. These results put forth the necessity of questioning anxiety during polyclinic assessment of complicated patients with Parkinson disease who have been undergoing treatment for long periods of time.

It was determined in another study carried out with 636 patients with Parkinson disease that the ratio of sleep disorder among patients with Parkinson disease was higher at a statistically significant level compared with the control group. While it was observed according to PSQI that $\mathrm{K} 1, \mathrm{~K} 4, \mathrm{~K} 5$ and $\mathrm{K} 7$ have been disrupted in patients with Parkinson disease; $\mathrm{K} 2$ has not been affected. This is an indication that sleeplessness observed among patients with Parkinson disease affects the unity and totality of sleep but does not have any impact on the start of sleep (33). It was observed in our study that the $\mathrm{K} 1$ and $\mathrm{K} 7$ scores were high at a statistically significant level in the patient group. K3 score was also determined to be high in the patient group but not at a statistically significant level. A statistically significant difference could not be determined between the K2, K4, K5, K6 scores. In conclusion, we observed in our study that the subjective sleep quality and daytime functions have been affected adversely at a statistically significant level in the Parkinson group. Even though sleep duration was disrupted in the Parkinson group, the difference was not statistically significant. A statistically significant difference could not be observed between the Parkinson and control groups with regard to sleep latency, sleep effectiveness, sleep disorder and use of medication. The acquired results were in accordance with the findings in literature. While it was observed in a study during which ESS and multiple sleep latency test (MSLT) were used for evaluating daytime sleepiness in patients with Parkinson disease that daytime sleepiness is observed in $46.3 \%$ of the patients according to ESS which is a subjective test; it was observed that the ratio decreased to $13.4 \%$ when MSLT is used which is an objective test (34). We also determined a high ratio of $53.85 \%$ in our study for daytime sleepiness according to ESS. Even though this is in accordance with literature, this may be due to the fact that an objective test was not used in our study for determining daytime sleepiness.

All components of PSQI were observed to be distinctively disrupted in patients with Parkinson disease in another study on sleep disorders. Highest score was observed in the daytime functions according to PSQI $(K 7=1.6)$. This was followed respectively by sleep disorders $(\mathrm{K} 5=1.3)$, sleep latency $(\mathrm{K} 2=1.2)$ and sleep quality $(\mathrm{K} 1=1.2)(37)$. It was also determined in our study in accordance with literature findings that daytime functions $(K 7=1)$ and sleep quality $(\mathrm{K} 1=1)$ scores were higher in the Parkinson group compared with the controls.

It was determined in our study that the ratio of insomnia is $27.5 \%$ among young patients with Parkinson disease, while this ratio was $55.2 \%$ among older adults with Parkinson disease. Insomnia, nightmares and RLS are observed less frequently in young-onset patients with Parkinson disease and they had better sleep quality (36). The mean age of the patients with Parkinson disease in our study was $68.14 \pm 7.01$ years. We are of the opinion that the advanced mean age of our study group is related with the negative results related with sleep disorders and daytime sleepiness. 
Similar to the findings in literature, daytime sleepiness was observed to be higher in patients with Parkinson disease in our study. Daytime sleepiness may have developed secondary to disrupted nighttime sleep. Pain, nocturia, RLS, obstructive sleep apnea syndrome, depression can be indicated as reasons for nighttime sleep disorder. These have to be examined and treated if possible in order to prevent daytime sleepiness. Daytime sleepiness may have also developed secondary to dopaminergic treatment. Finally, daytime sleepiness may develop due to the disease itself by affecting the sleep-wake cycle (37). Medications such as L-dopa and dopamine agonist that may lead to daytime sleepiness were not classified separately in our study. Even though this can be considered as a limitation, almost all of our patients were using L-dopa, dopamine agonist or both. Taking this into consideration, we thought that such a classification will not be very meaningful.

It was reported in a study carried out on 128 patients with Parkinson disease that $\mathrm{K} 2$ is correlated with the first section of UPDRS that reflects the mental state, behavior and mood. Similarly, a statistically significant relationship was determined between the first part of ISI and measured insomnia. A statistically significant relationship could not be determined between any part of UPDRS and daytime sleepiness measured via ESS (38). We also determined statistically significant relationships in our study between $\mathrm{K} 3$ and behavior and mood, between $\mathrm{K} 5$ and treatment complications. A statistically significant relationship could not be determined in our study between any section of UPDRS and insomnia measured via ISI and daytime sleepiness measured via ESS. In conclusion, sleep duration decreased in our patients with worsening mental state, behavior and mood. The ratio of sleep disorders increased with increasing treatment complications. The acquired findings in our study indicate that it is necessary to consider treatment complications when evaluating the patients with Parkinson disease with regard to sleep disorders.

Disease duration was determined to be correlated with K2 and K4 in another study (39). A statistically significant relationship could not be determined in our study between the disease duration and any component of PSQI. The impact of disease duration on any of the components of sleep could not be put forth in our study.

Nocturia was among the primary reasons for sleep disorders in older patients. ISI scores were determined to be correlated with urinary problems and constipation (38). The ISI scores of the control group in our study were higher at a statistically significant level. This may be due to the fact that majority of our patients were early stage patients with Parkinson disease and also to the fact that insomnia related with motor symptoms has not yet emerged. In addition, the fact that the control group was comprised of patient relatives and hospital employees may have resulted in the high ISI scores in this group.

The fact that medication use has not been reported in our study is a limitation. Another limitation of the study is that objective tests such as polysomnography have not been carried out to put forth sleep disorders. All of our patients were either early or medium stage patients with Parkinson disease according to HYS. This may have also been effective in the fact that insomnia and daytime sleepiness related with motor symptoms have not yet developed.

\section{CONCLUSION}

The presence of depression and anxiety should be questioned especially in more severe Parkinson patients who have been undergoing treatment for longer periods of time and the patients with treatment related complications should be evaluated with regard to sleep disorders. It should be kept in mind that the Parkinson disease is not comprised only of motor symptoms and that an effective treatment of non-motor symptoms will improve the quality of life of the patients significantly.

\section{ETHICAL DECLARATIONS}

Ethics Committee Approval: The study was performed by the local ethical committee of Bezmialem Vakıf University, including the number of the approval document and the date of the approval. (The registration number: 2011- KAEK-25 2019/01-03).

Informed Consent: All patients signed the free and informed consent form.

Conflict of Interest Statement: The authors have no conflicts of interest to declare.

Financial Disclosure: The authors declared that this study has received no financial support.

Author Contributions: All of the authors declare that they have all participated in the design, execution, and analysis of the paper, and that they have approved the final version.

Acknowledgment: We would like to thank Fikri Ak. neurology specialist.

\section{REFERENCES}

1. Scaravilli T, Gasparoli E, Rinaldi F, Polesello G, BraccoF. Healthrelated quality of life and sleep disorders in Parkinson's disease. Neurol Sci 2003; 24: 209-10.

2. Schulte EC, Winkelmann J. When Parkinson's disease patients go to sleep: Specific sleep disturbances related to Parkinson's disease. J Neurol 2011; 258: S328-S35.

3. Buysse DJ, Reynolds CF, Monk TH, Berman SR, Kupfer DJ. The Pittsburgh Sleep Quality Index: a new instrument for psychiatric practice and research. Psychiatry Res 1989; 28: 193-213. 
4. Johns MW. Reliability and Factor Analysis of the Epworth Sleepiness Scale. Sleep 1992; 15: 376-81.

5. Hogl B, Arnulf I, Comella C, et al. Scales to assess sleep impairment in Parkinson's disease: Critique and recommendations. Mov Disord 2010; 25: 2704-16.

6. Kalia LV, Lang AE. Parkinson's disease. Lancet 2015; 386: 896-912.

7. Yazar T, Olgun Yazar H. Evaluation of C-reactive protein/albumin ratio according to stage in patients with idiopathic Parkinson disease. Turk J Neurol 2019; 25: 123-8.

8. Defebvre L, Krystkowiak P. Movement disorders and stroke. Rev Neurol (Paris) 2016; 172: 483-7.

9. Leentjens AF. Depression in Parkinson's disease: conceptual issues and clinical challenges. J Geriatr Psychiatry Neurol 2004; 17: $120-6$.

10. Reijnders JS, Ehrt U, Weber WE, Aarsland D, Leentjens AF. A systematic review of prevalence studies of depression in Parkinson's disease. Mov Disord 2008; 23: 183-313.

11.Siciliano M, Trojano L, Santangelo G, De Micco R, Tedeschi G, Tessitore A. Fatigue in Parkinson's disease: a systematic review and meta-analysis. Mov Disord 2018; 33: 1712-23.

12. Samudra N, Patel N, Womack KB, Khemani P, Chitnis S. Psychosis in Parkinson disease: a review of etiology, phenomenology, and management. Drugs Aging 2016; 33: 855-63.

13.Egan SJ, Laidlaw K, Starkstein S. Cognitive behaviour therapy for depression and anxiety in Parkinson's disease. J Parkinsons Dis 2015; 5: 443-51.

14.Goodarzi Z, Mele B, Guo S, et al. Guidelines for dementia or Parkinson's disease with depression or anxiety: a systematic review. BMC Neurol 2016; 16: 244.

15.Seppi K, Weintraub D, Coelho M, et al. The Movement Disorder Society Evidence-Based Medicine Review Update: Treatments for the non-motor symptoms of Parkinson's disease. Mov Disord 2011; 26: S42-S80.

16.Stanković I, Petrović I, Pekmezović T, et al. Longitudinal assessment of autonomic dysfunction in early Parkinson's disease. Parkinsonism Relat Disord 2019; 66: 74-9.

17.Seppi K, Ray Chaudhuri K, Coelho M, et al. Update on treatments for nonmotor symptoms of Parkinson's disease-an evidencebased medicine review. Mov Disord 2019; 34: 180-98.

18. Forsaa EB, Larsen JP, Wentzel-Larsen T, et al. A 12-year population-based study of psychosis in Parkinson disease. Arch Neurol 2010; 67: 996-1001.

19. Deng X, Tang CY, Zhang J, et al. The cortical thickness correlates of clinical manifestations in the mid-stage sporadic Parkinson's disease. Neurosci Lett 2016; 633: 279-89.

20. Kim J, Jang S, Choe HK, Chung S, Son GH, Kim K. Implications of circadian rhythm in dopamine and mood regulation. Mol Cells 2017; 40: 450-6.

21.Tysnes OB, Storstein A. Epidemiology of Parkinson's disease. J Neural Transm (Vienna) 2017; 124: 901-5.

22.Lang AET, Fahn S. Assessment of Parkinson's disease in quantification of neurological deficit (ed TL munsat) Butterworts, Stoneham 1989: 285-309.

23. Akbostancı MC, Balaban H, Atbaşoğlu C. Interrater reliability of the Turkish version of the Motor Examination Section of Unified Parkinson's Disease rating scale and Abnormal Involuntary Movements scale. Parkinson Hastalığı ve Hareket Bozuklukları Derg 2000; 3: 7-13.

24. Hoehn MM, Yahr MD. Parkinsonism: Onset, progression and mortality. Neurology 1967; 17: 427-42.

25.Beck AT, Ward C, Mendelson M. Beck depression inventory (BDI). Arch Gen Psychiatry 1961; 4: 561-71.
26. Hisli N. Beck Depresyon Envanterinin üniversite öğrencileri için geçerliği, güvenirliği. Psikoloji Derg 1989; 7: 3-13.

27.Leentjens AF, Dujardin K, Marsh L, Richard IH, Starkstein SE, Martinez-Martin P. Anxiety rating scales in Parkinson's disease: a validation study of the Hamilton anxiety rating scale, the Beck anxiety inventory, and the hospital anxiety and depression scale. Mov Disord 2011; 26: 407-15.

28. Yazıcı MK, Demir B, Tanrıverdi N, Karaağaoğlu E, Yalaç P. Hamilton Anksiyete Değerlendirme Ölçeği, değerlendiriciler arası güvenirlik ve geçerlilik çalışması. Türk Psikiyatri Derg 1998; 9: 114-7.

29. İzci B, Ardic S, Firat H, Sahin A, Altinors M, Karacan I. Reliability and validity studies of the Turkish version of the Epworth Sleepiness Scale. Sleep Breath 2008; 12: 161-8.

30. Ağargün MY, Kara H, Anlar O. Pittsburgh Uyku Kalitesi İndeksi'nin geçerliği ve güvenirliği. Türk Psikiyatri Derg 1996; 7: 107-15.

31. Bastien $\mathrm{CH}$, Vallières A, Morin CM. Validation of the Insomnia Severity Index as an outcome measure for insomnia research. Sleep Med 2001; 2: 297-307.

32. Boysan M, Güleç M, Beşiroğlu L, et al. Psychometric properties of the Insomnia severity index in Turkish sample. Anadolu Psikiyatri Derg 2010; 11: 248-52.

33. Ratti PL, Nègre-Pagès L, Pérez-Lloret $S$, et al. Subjective sleep dysfunction and insomnia symptoms in Parkinson's disease: Insights from a cross-sectional evaluation of the French CoPark cohort. Parkinsonism Relat Disord 2015; 21: 1323-9.

34. Shen Y, Huang JY, Li J, Liu CF. Excessive daytime sleepiness in Parkinson's disease: clinical implications and management. Chin Med J (Engl) 2018; 131: 974-81.

35. Sveinbjornsdottir S. The clinical symptoms of Parkinson's disease. J Neurochem 2016; 139: 318-24.

36. Mahale R, Yadav R, Pal PK. Rapid eye movement sleep behavior disorder in young- and older-onset Parkinson disease: a questionnaire-based study. Sleep Med 2014; 15: 642-6.

37. Bargiotas P, Lachenmayer ML, Schreier DR, Mathis J, Bassetti CL. Sleepiness and sleepiness perception in patients with Parkinson's disease: a clinical and electrophysiological study. Sleep 2019; 42: zsz004.

38. Sobreira-Neto MA, Pena-Pereira MA, Sobreira EST, et al. Chronic insomnia in patients with Parkinson disease: which associated factors are relevant? J Geriatr Psychiatry Neurol 2020; 33: 22-7.

39. Bargiotas P, Schuepbach MWM, Bassetti CL. Sleep-wake disturbances in the premotor and early stage of Parkinson's disease. Curr Opin Neurol 2016; 29: 763-72. 